\title{
Research on Safety Education for Children Online Training Safety E-Learning
}

\author{
Qingmei Kong1, a * \\ ${ }^{1}$ Teacher's College, Beihua University, Jilin, China \\ a254519852@qq.com
}

\begin{abstract}
Keywords: Child safety education; online training; safety E-Learning
Abstract. Child safety education is always the top priority of school management in school. The children, especially the left behind children still faces many safety problems since there are many loopholes in the management of education. The child safety education model is proposed which is suitable for China's national conditions online training safety E-Learning security education, child safety education ways.
\end{abstract}

\section{Introduction}

Due to the time scale of foreign kindergarten games is very large, and their security education together with children's games, and more to do with living together, let children play in their own experience what is safe, and gradually form a security awareness, and the ability to cope with danger and the like.

In the theme is fire safety education for example. First, teachers and children to discuss any details about the fire safety of the children are interested in, such as fire drills what are the steps and how to escape the scene of the fire, which fire supplies; next in various games, the children can to experience content just discussed. In the arts, the children based on the video or pictures from the system and some fire-fighting products such as fire extinguishers, firemen, fire with long water pipe.

After the production, we can discuss these things they are used, their homemade fire supplies next role as game props, the teacher will prepare a large number of props for them, such as by a large cardboard box and four small chairs composed of fire, firefighters badge and so on. Role Play some children show firefighters. Practice how to use some of the fire fighting equipment, and some children are performers who fled the scene of a fire, escape of action or practice some self-help skills, such as pretending to roll off the body of the flames, lying on the floor to crawl like. In writing role, children can draw their own, or download some interesting pictures on fire safety from the Internet, then write their own story about these pictures, or plug-speak, tell you a story about fire safety. Some American nursery every semester there is a "fire Week", visit the nearby fire station, firefighters gave them a real fire drill, introduce some self-help skills, each child will have a fire album, coated paint Videos of the game, have some understanding of the fire safety knowledge.

Education Management objects from the perspective of rural children left behind large quantities of this special group. With the discovery of the economy and society, the number of migrant workers in the process more and more, the number of children left behind in rural areas has gradually increased, rural children left behind have constituted a special group. According to the survey, from the left-behind children in rural Shandong province quantitative point of view, "accounting for 33.71 percent of all children in rural areas, non-left-behind children accounted for $66.29 \%$ of the stage of the child.

Management of rural children left behind education problems is not the case, and public management process must draw attention to a group, but also the top-level design of public policies identified the need for specialized research. From the distribution of the characteristics of rural children left behind, the public administration must be involved in the process of rural children left behind education management into highly public policy. According to the survey, rural children left behind population is widely distributed, universal, public policy is not high quality, need to rely on the supervision and inspection, rural children left behind in the existing policies, at work most of the policy 
to file notification, in the form of instruction is issued the lack of substantive data for reference in relation to the supervision and evaluation work, and faced no special policy a policy specifically for rural children left behind basic public services proposed.

From rural children left behind education management organizations see shortage exist building. From a practical standpoint Towns, rural children left behind grassroots work is relatively weak, a limited number of rural children left behind caring service stations, fewer rural children left behind activity positions, the government's public administration in rural children left behind can only guarantee basic public service provision. The special nature of rural children left behind, leading to rural children left behind itself is minor, yet not fully protect their own interest demands, in addition guardian guardianship body is in an incomplete state, it is difficult also fully realized the children left behind in rural education management the specific circumstances of physical and mental development of children left behind in rural areas. Rural children left behind as the principal object of basic public services, must be present situation and trend analysis, to improve public services as an important part of the project, the existing policy of public service letter grip fine catch in place.

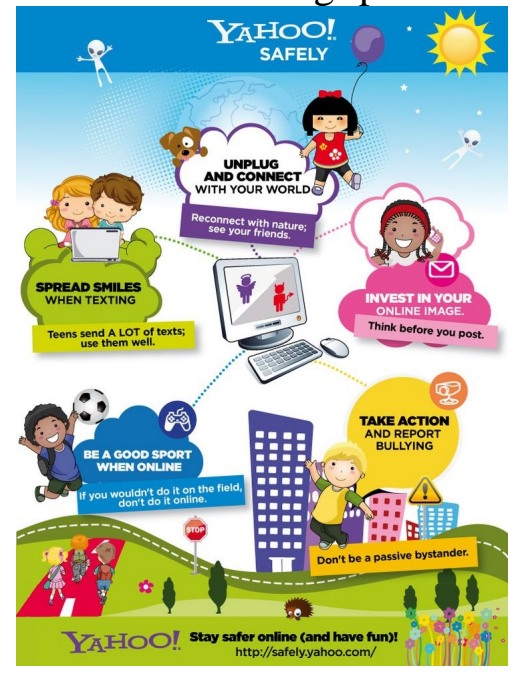

Fig. 1 Yahoo safely display interface

\section{The importance of education and management of rural children left behind}

Education for rural children left behind is a special historical period and the formation of specific social environment, especially urban-rural dual system and other factors constrained by, even though many migrant workers have long been living in the city, but their children because of residence, schooling is still under home follow grandparents or other guardians of life, in reality, migrant workers and their children only in two separate places, there is no effective way to be completely resolved. Rural Children are at a critical period of growth and development, from physical growth to mental health, to learn from life safety, from habituation to conduct shape, lack of positive parental intervention, life lack of communication, lack of emotional family care, the lack of value of ideological guidance, which makes rural children left behind in life growth is apt to cause abnormal cognitive, extreme, etc. character on the issue. Therefore, the public management functions that rural children left behind is a group can not be ignored, good management of rural children left behind education, providing them with appropriate public goods and public services, and ultimately benefit groups of children left behind in rural areas, can be directly Public managers within the existing institutional framework solution, ultimately resolve conflicts rural children left behind in public education management process, has a very important role. At the same time, rural children left behind is an extension of the "three rural" issues and derived, is the number of large groups of young people, is the importance of the relationship between development of the motherland "successors" strategic priority, education for rural children left behind can not be ignored.

Building a harmonious society and building a new socialist countryside inherent requirement. Rural Children are special vulnerable groups, they had a problem, and not only physical and psychological 
harm on their own, at the same time to the family, school, community and social harm, its large number of groups determine social contradictions problems caused by rural children left behind, certainly related to the realization of a harmonious society. Furthermore, rural children left behind and the "three rural" issues are closely related to the healthy growth of children left behind in rural areas, to promote a new socialist countryside construction has a positive role in promoting.

Through investigations found that rural children left behind the living conditions faced various problems from a more direct families, parents are out of time and guardians several factors, the improvement of the living conditions of rural children left behind to build a happy and harmonious new countryside has a direct relationship. Against 4222 survey found that rural children left behind, from the family income situation, belonging to poor families 238, 709 low-income families, accounting for the proportion of total $5.6 \%, 16.8 \%$, consider poor rural families and low-income families the proportion of cases of children left behind in rural family income is higher than the overall average, in fact, during the visit, I found that many migrant farmers engaged in manual labor in general more than the monthly income of 2,000 yuan, some technical jobs such as construction work days wage of 150 yuan, the annual revenue of at least 10 months Operators have more than 20,000 yuan, which is much higher than the per capita income of local farmers, in fact, rural children left behind because their parents work outside the family, the village compared to other household income is higher, which also Tip in the study of children left behind in rural areas should be avoided as children in difficult to treat. Parents from the family home situation, both parents work outside are 2926, only the father outside workers are 1229, only the mother has 67 overseas workers, living in rural children left behind more than half of the parents can not live together, And almost the majority can not live together with his father, which makes rural children left behind growing lack of parental life experience, especially the lack of experience with his father's life. Of which 2926 families both parents work outside the time point of view, there are 2004 less than one year, 1--3 years have 522, 400 more than three years, indicating that nearly a third of parents long (1 year) and can not live with their children for some time to compensate for the lack of common life experiences. From the perspective guardianship, custody of children left behind in rural types are four categories: First, the single-parent custody, that parent migrant workers, and the remaining one at home to look after children, which often lack the custody of the father or mother care education, so that children in character Formation of a problem; the second is generational custody, the grandfather, grandmother or grandfather, grandmother raising grandparents, whose parents were migrant workers, this approach is more common; the third is a relative custody, the parents of peers, such as uncles aunts and other relatives took the custody of a guardian in this way often occur in custody have concerns, not the biological child to let go of the hands and feet of discipline, so that children especially sensitive child psychology to depend on others to produce eccentric character; Fourth, peer monitoring, Some Gesao et guardianship older peers, in addition to the form of foster care or even unsupervised.

\section{Achieve educational equity, cultivate children age requirements}

Rural Children immediate families facing the problem of lack of education, combined with rural education should be improved to improve the impact of rural children left behind equitable access to education. Solve the problem of rural children left behind education management is to ensure that rural children left behind to enjoy more educational resources to the successful completion of nine years of compulsory basic schooling, help protect the right to education of children left behind in rural areas, in order to achieve a wider range on education equity. In addition, children are at a critical period of life physical and mental development, and data from a variety of studies and reports, there are a lot of children left behind in rural education management, rights protection, security, growth, and the realities of the resulting very worrying, In many aspects of life, learning, psychology, personality, etc. are there with other children do not have the problem, such as life unattended, prone to bad behavior, learning initiative is not strong, declining grades, psychological missing love, rebellious heavy, likely to cause selfish, indifferent nature alone, more than rural children left behind also easy to make appear pessimistic, stoop disadvantage. 


\section{Summary}

Management of rural children left behind education is directly related to the growth of their own health; the relationship between rural children left behind every family behind, but also related to the success of the new comprehensive deepening the reform process in rural education is related to the construction of new socialist countryside process. In carrying out a period of more than two years of rural children left behind education service work, personally visited for the survey, the lack of educational resources in rural feel, difficult children live in rural areas, the lack of family care for rural children left behind, and started to have carried out a number of rural Study on Children Left Behind education management, some envisage also conducted field attempts, it had some effect. From a practical perspective, under the existing national policy environment (such as household registration, etc.), cities and counties can not formulate policies and regulations, but directly to solve the problem of left-behind children in rural areas, which requires local governments and other parties must address the issue, positive study measures within the existing system, public policy, and actively improve the environment for the education and management of rural children left behind. Of course, the problem of children left behind in rural areas is widespread across the country, government, schools, families and the whole society should strengthen care and support for children left behind in rural areas, continue to improve their living and learning conditions and promote physical and mental development of children left behind in rural areas.

\section{References}

[1] Gong Weibin Rural Farm Employment Change and Family Relations. Sociological Research, 1999 (1).23-27.

[2] Built by Yan Shi Sheng: Problems and Development Strategies of Rural Education in West China Exploration. Anhui Agricultural Sciences, 2007.45-49.

[3] Wu Yonghua: "service-oriented government in the rural left-behind children Responsibility and Measures". the charm of China, 2010 (17),125-129.

[4] Pei,et al: Emotional minority areas behind children's ability to regulate and social adjustment. Anqing Teachers College (Social Science Edition), 2010 (6),320-325.

[5] Moderating Sun Xiaojun, Fan Cuiying rural left-behind children's mental development problems and countermeasures. South China Normal University, 2007 (06),15-19.

[6] Gilbert, Fengli Ting environmental factors in rural left-behind children's psychological development impact. Guizhou Normal University, 2008 (05),23-28.

[7] Tao trends early childhood education in rural areas and attributed equity Perspective.preschool education research, 2006, (2): 42-46.

[8] He owned bridge. Huang Ning. Cao Zhongping Comparative adaptability of migrant children and urban children learning. Chinese Journal of Clinical Psychology, 2007,15 (5),23-26. 